\title{
Memory Retrieval Has a Dynamic Influence on the Maintenance Mechanisms That Are Sensitive to $\zeta$-Inhibitory Peptide (ZIP)
}

\author{
David Levitan, ${ }^{1 \star}$ Yaihara Fortis-Santiago, ${ }^{1 *}$ Joshua A. Figueroa, ${ }^{1}$ Emily E. Reid, ${ }^{2}$ Takashi Yoshida, ${ }^{4}$ \\ Nicholas C. Barry, ${ }^{1}{ }^{-}$Abigail Russo, ${ }^{2}$ and Donald B. Katz ${ }^{1,2,3}$ \\ ${ }^{1}$ Program of Neuroscience, ${ }^{2}$ Department of Psychology, and ${ }^{3}$ Volen Center for Complex Systems, Brandeis University, Waltham, Massachusetts 02454
}

In neuroscientists' attempts to understand the long-term storage of memory, topics of particular importance and interest are the cellular and system mechanisms of maintenance (e.g., those sensitive to $\zeta$-inhibitory peptide, ZIP) and those induced by memory retrieval (i.e., reconsolidation). Much is known about each of these processes in isolation, but less is known concerning how they interact. It is known that ZIP sensitivity and memory retrieval share at least some molecular targets (e.g., recycling $\alpha$-amino-3-hydroxy-5-methyl-4isoxazolepropionic acid, AMPA, receptors to the plasma membrane); conversely, the fact that sensitivity to ZIP emerges only after consolidation ends suggests that consolidation (and by extension reconsolidation) and maintenance might be mutually exclusive processes, the onset of one canceling the other. Here, we use conditioned taste aversion (CTA) in rats, a cortically dependent learning paradigm, to test this hypothesis. First, we demonstrate that ZIP infusions into gustatory cortex begin interfering with CTA memory 43-45 $\mathrm{h}$ after memory acquisition-after consolidation ends. Next, we show that a retrieval trial administered after this time point interrupts the ability of ZIP to induce amnesia and that ZIP's ability to induce amnesia is reengaged only $45 \mathrm{~h}$ after retrieval. This pattern of results suggests that memory retrieval and ZIP-sensitive maintenance mechanisms are mutually exclusive and that the progression from one to the other are similar after acquisition and retrieval. They also reveal concrete differences between ZIP-sensitive mechanisms induced by acquisition and retrieval: the latency with which ZIP-sensitive mechanisms are expressed differ for the two processes.

Key words: consolidation; memory; reconsolidation; retrieval; ZIP

\section{Significance Statement}

Memory retrieval and the molecular mechanisms that are sensitive to $\zeta$-inhibitory peptide (ZIP) are the few manipulations that have been shown to effect memory maintenance. Although much is known about their effect on maintenance separately, it is unknown how they interact. Here, we describe a model for the interaction between memory retrieval and ZIP-sensitive mechanisms, showing that retrieval trials briefly (i.e., for $45 \mathrm{~h}$ ) interrupt these mechanisms. ZIP sensitivity emerges across a similar time window after memory acquisition and retrieval; the maintenance mechanisms that follow acquisition and retrieval differ, however, in the latency with which the impact of ZIP is expressed.

\section{Introduction}

Memory is composed of (at least) two phases, each sensitive to distinct molecular and behavioral perturbations. Long-term

\footnotetext{
Received May 13, 2016; revised Aug. 25, 2016; accepted Aug. 28, 2016.

Author contributions: D.L., Y.F.-S., and D.B.K. designed research; Y.F.-S., J.A.F., E.E.R., T.Y., N.C.B., and A.R. performed research; D.L. contributed unpublished reagents/analytic tools; D.L., Y.F.-S., and D.B.K. analyzed data; D.L., Y.F.-S., and D.B.K. wrote the paper.

This work was funded by the National Institutes of Health (Grant DC-006666) and the Leir Foundation (BrandeisIsrael initiative Fellowship). We thank Selin Neseliler and Benjamin Rubin for assistance, Leslie Griffith for helpful advice, and Sacha Nelson for helpful comments.

The authors declare no competing financial interests.

${ }^{*}$ D.L. and Y.F.-S. contributed equally to this work.

Correspondence should be addressed to either Prof. Donald B. Katz or Dr. David Levitan, Program of Neuroscience, Volen Center for Complex Systems, Brandeis University, 415 South Street, Waltham, MA 02454; E-mail: dbkatz@brandeis.edu or levitand@brandeis.edu.
}

memory formation is dependent on transcription and translation taking place immediately after memory acquisition trials in a process termed consolidation. Maintenance, the phase that follows consolidation, is characterized by stability in the face of the molecular and behavioral perturbations (e.g., protein synthesis inhibition and retroactive interference) that inhibit consolidation (Alberini, 2009; Nader and Hardt, 2009; Gal-Ben-Ari et al., 2012).

Once memory reaches the maintenance phase, very few manipulations can perturb that memory. One such manipulation is memory retrieval itself (Spear, 1973; Sara, 2000), which starts a process called reconsolidation (Dudai, 2006; Nader and Hardt, 
2009; Alberini and Ledoux, 2013) during which memory strength (Inda et al., 2011; Fukushima et al., 2014) and persistence (Levitan et al., 2010) can once again be modified. Another maintenance inhibitor is $\zeta$-inhibitory peptide (ZIP, which mimics the pseudosubstrate sequence of the regulatory subunit of PKC $\zeta$ ); infused into learning-relevant brain regions, ZIP has no impact on consolidation, but impairs memory maintenance (Shema et al., 2007; Sacktor, 2011; Serrano et al., 2008; Migues et al., 2010; Kwapis and Helmstetter, 2014). This impact of ZIP on maintenance is robust and reliable, although the molecular mechanisms underlying that effect are a matter of some controversy (see Discussion).

Whereas retrieval and ZIP have each been studied extensively, little work has probed the relationship between the two and, although each might act through distinct mechanisms, it may be that the molecular pathways underlying the impact of ZIP (Yao et al., 2008; Migues et al., 2010) and reconsolidation (Rao-Ruiz et al., 2011; Hong et al., 2013) converge to have opposing impacts upon the same target (e.g., the trafficking of GluR2-containing AMPA receptors to activated synapses). It is therefore reasonable to hypothesize that retrieval could specifically antagonize ZIP sensitivity. Because ZIP has no impact on consolidation, it is reasonable to hypothesize that its impact could be abolished when maintenance gives way to reconsolidation.

Here, we have explicitly tested this hypothesis using conditioned taste aversion (CTA), in which a normally appetitive taste is rendered aversive after being paired with gastric distress. CTA maintenance is known to be sensitive to ZIP injection into gustatory cortex (GC) (Shema et al., 2007) and both consolidation (Rosenblum et al., 1993) and reconsolidation (Eisenberg et al., 2003) of CTA memory are dependent on the function of the GC; here, we examined the impact of memory retrieval on the memory-erasing efficacy of ZIP infusions into GC. We first explored the dynamics of the impact of ZIP on CTA, showing that it becomes an effective amnesic agent at $\sim 45 \mathrm{~h}$ after training. Next, after confirming that a single memory retrieval trial indeed induces reconsolidation, we showed that that same retrieval trial temporarily disrupts the memory's sensitivity to ZIP. ZIP sensitivity then reemerges with a similar latency as after memory acquisition. These results suggest similarities between the processes induced by memory acquisition and retrieval; they reveal concrete differences between the two as well, however, in that the latency with which ZIP-sensitive mechanisms are expressed differ for the two processes.

\section{Materials and Methods}

Subjects. In all experiments, female Long-Evans rats (Charles River Laboratories) weighing between 250 and $300 \mathrm{~g}$ at the time of surgery served as subjects. All were individually housed and kept on a 12/12 h light/dark cycle (experiments during artificial daylight). All methods complied with Institutional Animal Care and Use Committee at Brandeis University.

Cortical cannulation. Rats were anesthetized with intraperitoneal injections of a ketamine/xylazine/acepromazine $(100 \mathrm{mg} / \mathrm{kg}, 5 \mathrm{mg} / \mathrm{kg}$, and $1 \mathrm{mg} / \mathrm{kg}$, respectively) or ketamine/xylazine $(100 \mathrm{mg} / \mathrm{kg}, 5 \mathrm{mg} / \mathrm{kg}) \mathrm{mix}-$ ture. Update doses of the mixture $(20 \% \times$ dose $)$ given as needed helped to maintain anesthesia. The anesthetized rat was placed in a stereotaxic frame, the scalp incised and retracted, and the skull leveled. Two to five support screws were implanted and guide cannulae (23 gauge, $15 \mathrm{~mm}$ long) were lowered bilaterally into gustatory cortex (AP: $1.4 \mathrm{~mm}, \mathrm{ML} \pm$ $5.0 \mathrm{~mm}, \mathrm{DV}-4.0$ to $4.5 \mathrm{~mm}$ from dura) and anchored with dental acrylic. Stylets inserted into the guide cannulae ensured patency. Rats with at least one mistargeted cannula (see Fig. 4 for histological details) were excluded from analysis.
CTA. After $5 \mathrm{~d}$ recovery from surgery, rats were given 3-4 adaptation days ( $30 \mathrm{~min}$ access to $15 \mathrm{ml}$ of $\mathrm{dH}_{2} \mathrm{O}$ from a single lick spout in a sound-isolated test chamber). Subjects received another $10 \mathrm{~min}$ of water in their home cages in the evening. The training session was identical to adaptation sessions, but the $\mathrm{dH}_{2} \mathrm{O}$ was replaced with $0.10 \%$ saccharin. An intraperitoneal injection of $0.15 \mathrm{M} \mathrm{LiCl}(20 \mathrm{ml} /$ $\mathrm{kg}$ ) was delivered $40 \mathrm{~min}$ after the drinking session. Twenty-four, 48, or $72 \mathrm{~h}$ later, rats were again presented with $0.10 \%$ saccharin ("Test"). A reduction in consumption during the Test trial (compared with training) revealed learned aversions to the saccharin; any inhibition of learning caused by ZIP would be to reduce the difference in consumption between the training and testing sessions (i.e., to increase consumption on the Test trial).

Reconsolidation. Retrieval trial set reconsolidation in motion. A retrieval trial, identical to the test trials given in Fig. 1, was given to the animals $48 \mathrm{~h}$ after acquisition and was followed by anisomycin or vehicle infusion to the GC. Memory was tested 24 h later (Test 1 ) which was followed by three extinction trials (Tests $2-4$ separated $24 \mathrm{~h}$ apart).

Gustatory cortical microinfusions. At particular time points (see text), rats were held in the experimenter's lap and infusion cannulae were inserted into the surgically implanted cannulae. ZIP $(10 \mathrm{nmol} / \mu$; Tocris Bioscience) or PBS vehicle was infused at a rate of $1 \mu \mathrm{l} / \mathrm{min}$ for $1 \mathrm{~min}$. Anisomycin (125 $\mu \mathrm{g} / \mu \mathrm{l}$; Sigma-Aldrich) was dissolved in an equimolar solution of $\mathrm{HCl}, \mathrm{pH} 7.2$, and brought to the final concentration with PBS and infused at a rate of $0.25 \mu \mathrm{l} / \mathrm{min}$ for $1 \mathrm{~min}$. Infusion cannulae were left in place for an additional minute after the infusions to allow the infusant to diffuse away from the cannula tips.

Statistics. All effects were evaluated using either paired $t$ tests or, if appropriate, two-way ANOVAs or two-way repeated-measures ANOVAs.

Histology. Anesthetized rats were perfused with $10 \%$ saline followed by formalin. Removed brains were refrigerated in $30 \%$ sucrose $/ 10 \%$ formalin solution for several days and coronal sections $(40 \mu \mathrm{m})$ were mounted to slides. Sections were stained with cresyl violet to visualize somata and the coordinates of the cannula tips were mapped on the corresponding bregma plane in the Paxinos and Watson rat atlas (Paxinos and Watson, 2007).

\section{Results}

\section{CTA induces a ZIP-sensitive maintenance phase}

The aim of this study was to probe for interactions between memory retrieval and the maintenance mechanisms that are sensitive to ZIP. As a first step toward comparing preretrieval and postretrieval mechanisms, we investigated the time course of CTA memory's sensitivity to ZIP.

Long-term memory is thought to be composed of two key processes, consolidation and maintenance, occurring at distinct times and underlain by distinct molecular mechanisms. An often-postulated distinction between the two regards the unique dependence of the former on de novo protein synthesis (Alberini, 2009; Nader and Hardt, 2009; Gal-Ben-Ari et al., 2012). In most paradigms tested, protein synthesis inhibitors stop having amnestic properties at the most $24-48 \mathrm{~h}$ after acquisition, a fact that has led multiple researchers to conclude that memory consolidation reaches completion at that time (Bambah-Mukku et al., 2014 Kwapis and Helmstetter, 2014; Levitan et al., 2016); we refer to this time point as the "putative" end of consolidation.

In stark contrast to the action of protein synthesis inhibitors, injections of ZIP into learning-relevant brain regions, including (depending on the task) the hippocampus (Serrano et al., 2008) and amygdala (for summary, see Sacktor, 2011; Migues et al., 2010; Kwapis and Helmstetter, 2014) appear to impair memory maintenance uniquely. That is, the amnesic effect of ZIP can be observed only when the injection is given $>24 \mathrm{~h}$ after memory acquisition, after the putative completion of consolidation. In studies using CTA as a learning paradigm, the relevant region is the GC, a central node of the taste-learning circuit (Berman and 

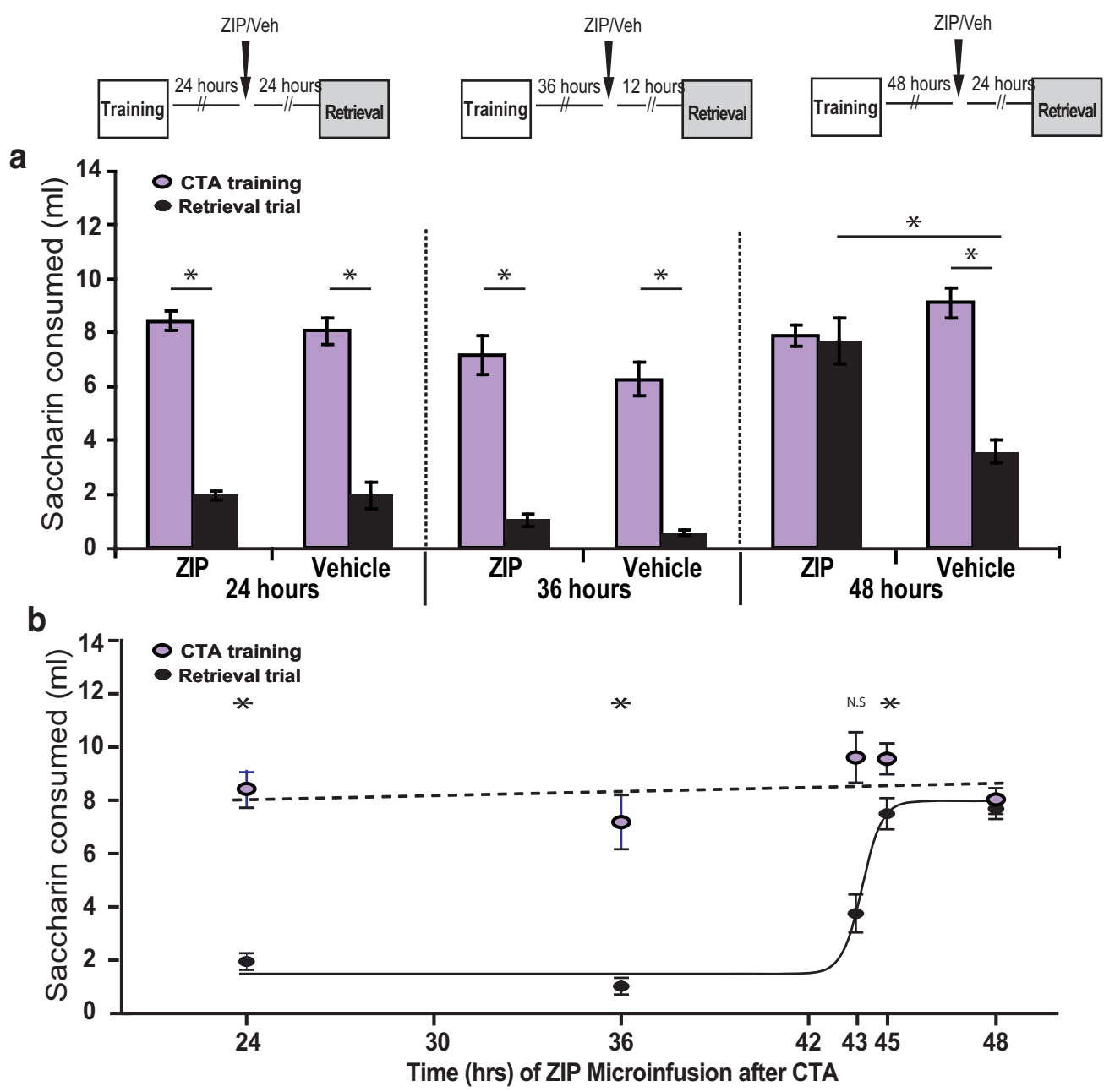

Figure 1. Erasure of memory via ZIP infusion into $\mathrm{GC}$ emerges across the $2 \mathrm{~d}$ after training. $\boldsymbol{a}, \mathrm{ZIP}(1 \mu \mathrm{l} ; 10 \mathrm{nmol}$ bilaterally) or vehicle control ( $1 \mu$; PBS bilaterally) was infused to $\mathrm{GC} 24 \mathrm{~h}$ (ZIP, $n=4$; vehicle, $n=3$ ) or $36 \mathrm{~h}$ (ZIP, $n=4$; vehicle, $n=3$ ) after (TA training ( $30 \mathrm{~min}$ of $0.1 \%$ saccharin consumption that was followed by $0.15 \mathrm{~m} \mathrm{LiCl,} 2 \%$ body weight, i.p.). When tested for CTA memory $48 \mathrm{~h}$ after training by comparing saccharin consumption between CTA training day and retrieval trial, both the ZIP and vehicle groups had comparable CTA memory. When animals were infused (ZIP, $n=8$; vehicle, $n=7$ ) $48 \mathrm{~h}$ after training and tested $24 \mathrm{~h}$ later, only the control group learned, indicating that (TA memory was erased. $\boldsymbol{b}$, CTA sensitivity to ZIP emerges between 43 and $45 \mathrm{~h}$ after memory acquisition. Comparison of CTA memory (expressed as the difference in saccharin consumption between CTA training and retrieval trial groups) after ZIP injection at different time points is shown. All data points are taken from $\boldsymbol{a}$. ${ }^{*}$ Significant difference according to $t$ test or ANOVAs $(p<0.05)$. See text for further details on statistics.

Dudai, 2001; Moran and Katz, 2014; for review, see Gal-Ben-Ari and Rosenblum, 2011). Previous studies have revealed that ZIP fails to induce amnesia when infused $100 \mathrm{~min}$ after memory acquisition, but does so when infused $72 \mathrm{~h}$ afterward (Shema et al., 2007, 2009), a time window in which memory consolidation has putatively reached completion (Rosenblum et al., 1993; BambahMukku et al., 2014; Levitan et al., 2016). As a part of more accurately delineating the time course of this effect, we first investigated the impact of injecting ZIP into GC at a range of time between 24 and $48 \mathrm{~h}$ after CTA acquisition.

As displayed in Figure 1, we injected ZIP ( $1 \mu \mathrm{l} ; 10$ nmol bilaterally) or vehicle (PBS) to the GC at a range of time points after a single CTA training trial (30 min of $0.1 \%$ saccharin consumption followed immediately by an intraperitoneal injection of $0.15 \mathrm{M} \mathrm{LiCl}, 2 \%$ body weight) and tested the strength of the memory (reduction of saccharin consumed) with a retrieval trial given $48 \mathrm{~h}$ after acquisition. A group that received injections $48 \mathrm{~h}$ after acquisition was tested $24 \mathrm{~h}$ later to control for possible acute, transient effects of ZIP.

Rats receiving ZIP infusions 24 or $36 \mathrm{~h}$ after training (Fig. $1 a, b)$ developed strong CTAs equal in magnitude to rats in the same group that received control infusions (2-way ANOVAs re- vealed that the only significant effect in either the 24 or $36 \mathrm{~h}$ was session: $F_{(1,13)}=62.3, p<0.01$ and $F_{(1,13)}=29.9, p<0.05$, respectively). That is, ZIP had no impact on learning in these groups. Ancillary pairwise tests showed all of the expected learning effects (each $t>4.9$, each $p<0.04$ ), with no consumption differences observed in retrieval trials between groups (each $t<$ 1). Subsequent tests showed no significant difference between ZIP and vehicle groups in either experiment (injection 24 and $36 \mathrm{~h}$ after CTA acquisition) in a second retrieval trial $24 \mathrm{~h}$ later. The average Test 2 consumption in the ZIP and control groups differed by only $0.2-0.3 \mathrm{ml}$ in these experiments, values much smaller than the SE estimates of 1-2 ml, further confirming that ZIP has no effect on memory when injected at these time points.

In contrast, by $48 \mathrm{~h}$ after memory acquisition, ZIP injection had a strong effect on CTA memory tested $24 \mathrm{~h}$ later (Fig. 1a, far right). Rats receiving ZIP injections $48 \mathrm{~h}$ after training demonstrated no evidence of learned aversions to saccharin: 2-way ANOVA comparing the ZIP- and control-infused rats revealed a main effect of session $\left(F_{(1,29)}=10.9, p<0.01\right)$ and a session $\times$ group interaction $\left(F_{(1,29)}=\right.$ 9.53, $p<0.05)$; subsequent pairwise tests revealed that only the control group learned $\left(t_{(6)}=6.26, p<0.01\right)$. 

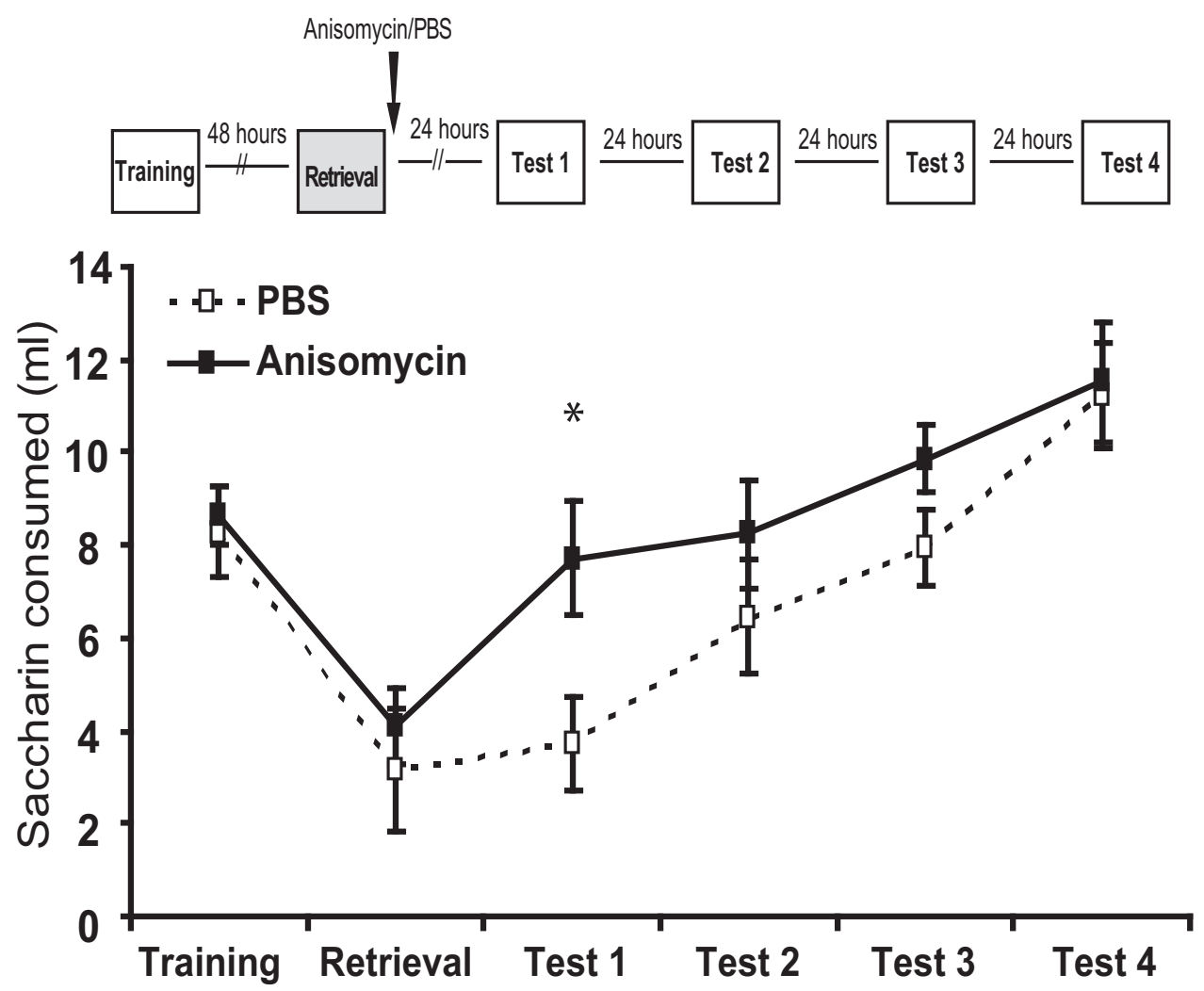

Figure 2. CTA retrieval induces memory reconsolidation. Anisomycin ( $1 \mu \mathrm{l} ; 1.25 \mu \mathrm{g}$ bilaterally) or vehicle control ( $1 \mu$ l; PBS bilaterally) was infused into the $\mathrm{GC}$ immediately after CTA retrieval. Twenty-four hours later, animals were subjected to daily testing for 5 consecutive days. We found significant reduction in the aversion toward saccharin in the first test day, confirming reconsolidation of CTA memory.

In previous reports, the effect of ZIP could be detected as few as 2-3 h after ZIP infusion (Shema et al., 2007; Serrano et al., 2008). In more precisely delineating the onset of ZIP efficacy after the acquisition trial, we showed that our preparation and data conformed to the expectation set up by this earlier work. We found that ZIP infusion $45 \mathrm{~h}$ after learning reduced CTA memory slightly when tested $3 \mathrm{~h}$ later: ZIP rats consumed more in the retrieval trial than control rats $\left(t_{(19)}=-1.9, p=0.03\right)$, indicating that a modest ZIP-induced amnesia could be detected; retrieval consumption in ZIP rats was $6.13 \pm 0.76 \mathrm{ml}$ (in control rats, it was $3.95 \pm 0.96 \mathrm{ml}$ ), which was still less than training session consumption $(10.14 \pm 0.70 \mathrm{ml})$. The effect of ZIP infusion at $43 \mathrm{~h}$ after learning was even smaller and in fact failed to reach significance (Fig. 1b).

In summary, the molecular mechanisms that allow ZIP to induce amnesia come into play between 43 and $45 \mathrm{~h}$ after memory acquisition, after memory has consolidated (Rosenblum et al., 1993; Bambah-Mukku et al., 2014; Levitan et al., 2016). This impact is expressed as soon as $3 \mathrm{~h}$ after ZIP injection. ZIPsensitive mechanisms in the GC play an important role in CTA memory maintenance, but not in consolidation.

\section{CTA retrieval induces memory reconsolidation and} interrupts ZIP-sensitive maintenance mechanisms for $\mathbf{4 5} \mathrm{h}$ The retrieval of a memory can itself have a profound effect on the long-term maintenance of that memory (Spear, 1973) by inducing reconsolidation processes (Sara, 2000; Dudai, 2006; Nader and Hardt, 2009; Alberini and Ledoux, 2013). During reconsolidation, memories once again become labile and protein-synthesisdependent processes similar to those in play during consolidation to "reconsolidate" the original trace such that application of a protein synthesis inhibitor after retrieval test impairs subsequent memory retrieval (Nader et al., 2000; Eisenberg et al., 2003; Levitan et al., 2010; Inda et al., 2011).

To confirm that our retrieval protocol actually induces reconsolidation, we trained two groups of rats and tested CTA memory $24 \mathrm{~h}$ later. We injected the protein synthesis inhibitor anisomycin ( $1 \mu \mathrm{l} ; 1.25 \mu \mathrm{g}$ bilaterally) or vehicle control ( $1 \mu \mathrm{l}$; PBS bilaterally) into the GC during this first retrieval test. Figure 2 shows memory measured at subsequent retrieval tests (labeled Tests 1-4), revealing that blocking protein synthesis during retrieval results in significant reduction in the aversion toward saccharin in the first test day (anisomycin group vs vehicle group; $t_{(23)}=2.4, p<$ $0.03)$. Given that anisomycin has been reliably shown not to cause amnesia when injected $24 \mathrm{~h}$ or more after training, a result confirmed both in general (Nader et al., 2000; Levitan et al., 2010; Bambah-Mukku et al., 2014) and GC infusions after CTA (Rosenblum et al., 1993; Berman and Dudai, 2001; Levitan et al., 2016), we conclude that one retrieval trial initiates CTA reconsolidation processes in our paradigm.

Having established that reconsolidation occurs in our CTA paradigm, we tested the immediate (and delayed) impact of this induction on ZIP-sensitive maintenance processes. Specifically, we performed analogous experiments to those described above, injecting ZIP or vehicle control to GC at a range of time points (in different groups of rats) after the retrieval trial. The results of these experiments clearly demonstrate that retrieval effectively and immediately eliminates the ZIP efficacy that had emerged $45 \mathrm{~h}$ after acquisition. When infusions were delivered $1 \mathrm{~h}$ after retrieval, we found no significant difference between the ZIP and 


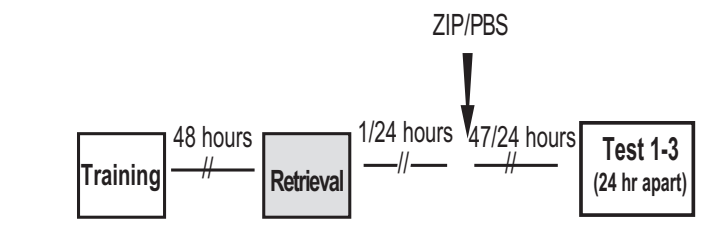

a
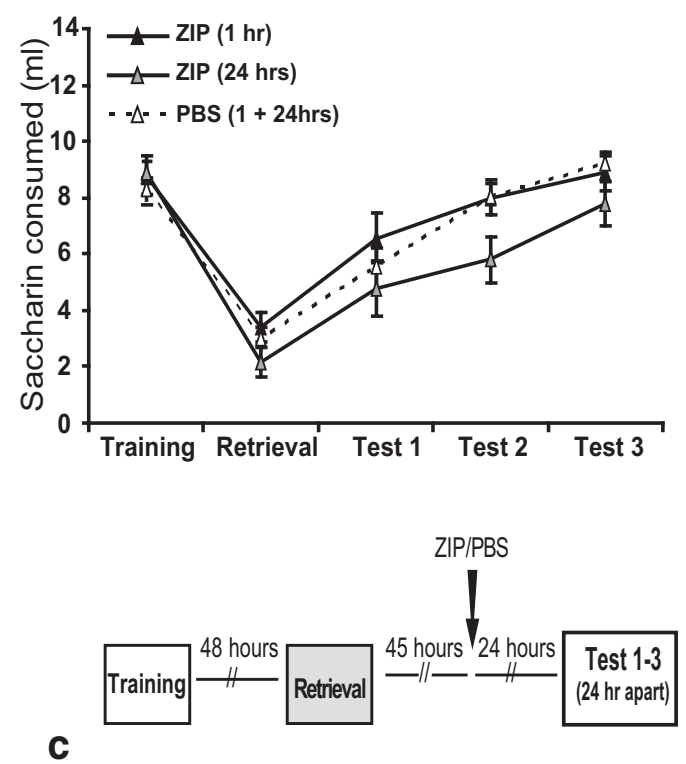

C

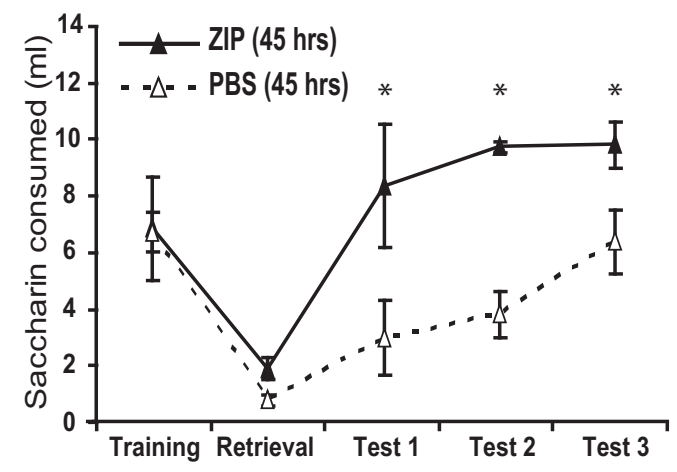

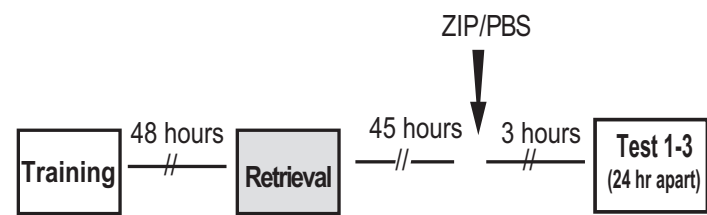

b

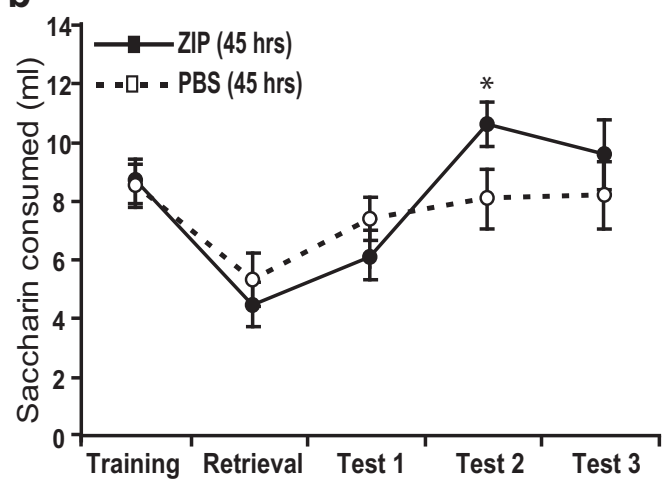

Figure 3. Memory retrieval interrupts ZIP-sensitive maintenance mechanisms for $45 \mathrm{~h} . \boldsymbol{a}$, Loss of memory sensitivity to ZIP 1 and $24 \mathrm{~h}$ after retrieval ZIP or vehicle controls were infused to the GC $1 \mathrm{~h}$ ( $n=15$ /group) or $24 \mathrm{~h}$ (ZIP, $n=10$; vehicle, $n=9$ ) after CTA memory retrieval and tested daily for 3 consecutive days. We found that both the ZIP and vehicle groups had normal memory and extinction, with no significant differences between the groups. $\boldsymbol{b}$, Memory become sensitive to ZIP $45 \mathrm{~h}$ after retrieval only when tested 24 but not $3 \mathrm{~h}$ later. ZIP or vehicle ( $n=14 / \mathrm{group}$ ) was infused to the GC $45 \mathrm{~h}$ after CTA memory retrieval and tested $3 \mathrm{~h}$ later and for 2 consecutive days. There was only a significant effect between the groups in in Test $224 \mathrm{~h}$ after Test 1 . c, Memory become sensitive to ZIP $45 \mathrm{~h}$ after retrieval only when tested 27 later. ZIP or vehicle (ZIP, $n=3$; vehicle, $n=6$ ) was infused into the $\mathrm{GC} 45 \mathrm{~h}$ after CTA memory retrieval and tested $27 \mathrm{~h}$ later (Test 1 ) and for 2 consecutive days (Test 2 and Test 3 ). There was significant reduction in saccharin consumption in the ZIP group compared with the vehicle group $27 \mathrm{~h}$ after the injection.

control groups tested $47 \mathrm{~h}$ later; in fact, this infusion had no impact on the course of CTA extinction tested across 3 successive days $\left(F_{\text {session }(4,112)}=52.1, p<0.01\right.$; no effects of group; Fig. $\left.3 a\right)$. Results were essentially identical when the infusion was delivered $24 \mathrm{~h}$ after retrieval and tested $24 \mathrm{~h}$ later: both the ZIP and control groups expressed normal memory and memory extinction (2way ANOVA effect of session $F_{(3,51)}=39.9, p<0.01$; group by session interaction $F<1$; Fig. 3). Retrieval almost immediately renders ZIP ineffective and this lack of efficacy persists for at least $24 \mathrm{~h}$ after CTA retrieval. The onset of reconsolidation processes caused by retrieval apparently blocks the ZIP-sensitive mechanisms that are important for memory maintenance.

The work described in Figure 1 demonstrates that ZIP becomes an effective amnestic agent when infused into the GC close to $45 \mathrm{~h}$ after memory acquisition, a time point that could be argued to represent the end of the consolidation phase (Rosenblum et al., 1993; Bambah-Mukku et al., 2014; Levitan et al., 2016) and the onset of the maintenance phase of CTA memory. The central hypothesis of this work was that reconsolidation might itself give way to an analogous, ZIP-sensitive maintenance phase. To test this hypothesis, we injected ZIP or vehicle control into GC $45 \mathrm{~h}$ after memory retrieval. In doing so, we discovered both a broad similarity and specific difference between consolidation and reconsolidation: whereas ZIP-induced amnesia could be detected as fast as $3 \mathrm{~h}$ after an injection made $45 \mathrm{~h}$ after acquisition (Fig. $1 b$ ), an analogous experiment showed ZIP to have little effect on CTA memory tested $3 \mathrm{~h}$ after a $45 \mathrm{~h}$ postretrieval infusion. A test performed $24 \mathrm{~h}$ later in the same rats, however, revealed a significant ZIP versus control effect (2-way ANOVA main effect of session $\left.F_{(2,52)}=17.2, p<0.01\right)$ and a group by 

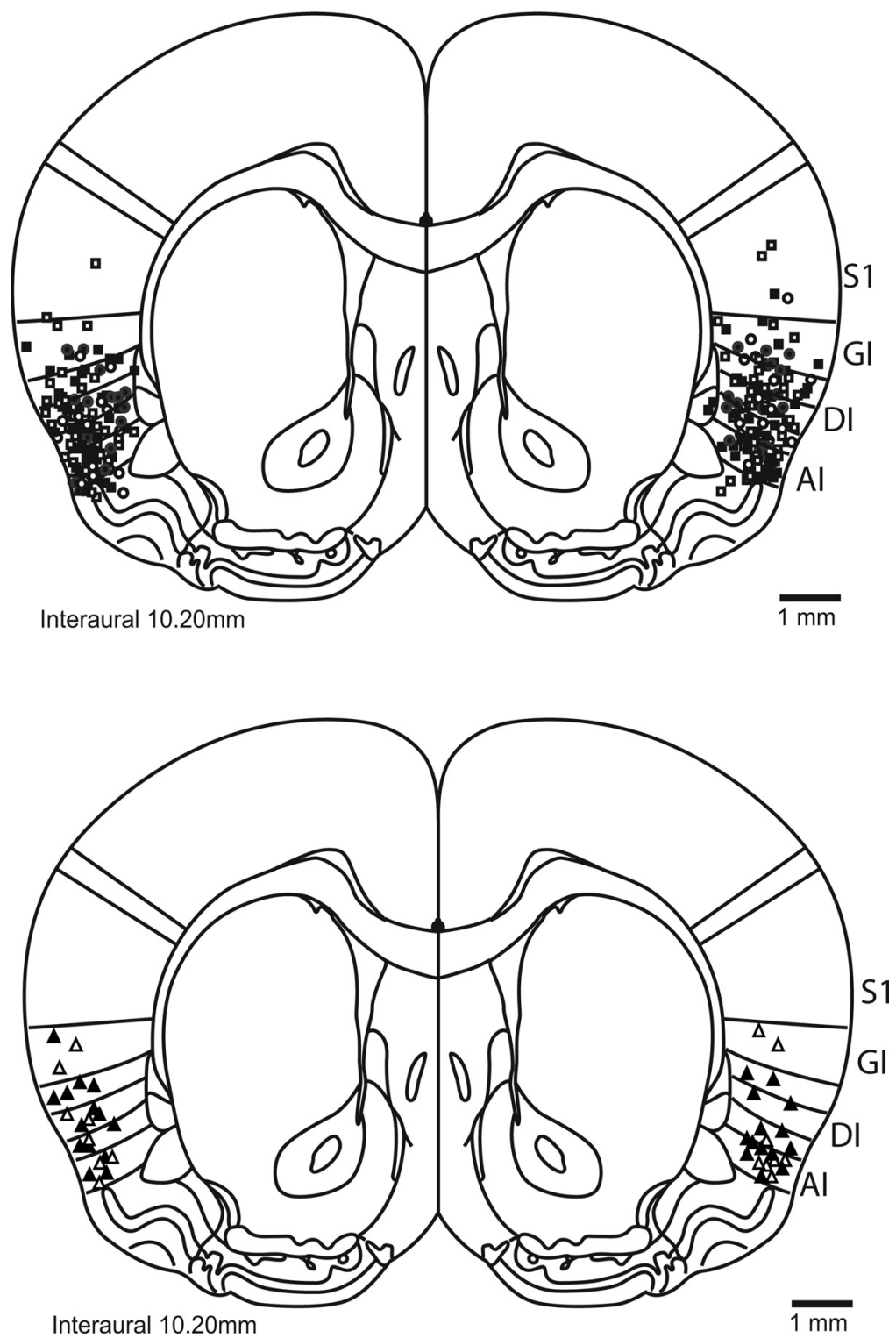

Figure 4. Cannula placement in the rat GC. A schematic (reprinted with permission from Paxinos and Watson, 2007) of the rat brain at the level of GC (Katz et al., 2001) shows the locations of most infusions; rats in which infusions missed gustatory cortex (i.e., granular, agranular, and dysgranular insular) were excluded from analyses. S1, Somatosensory cortex; GI/AI/DI, granular/agranular/dysgranular insular cortex.

session interaction $\left(F_{(2,52)}=3.9, p<0.03\right.$; Fig. $\left.3 b\right)$. That is, ZIP is once again effective $45 \mathrm{~h}$ after reminder, but the latency between ZIP infusion and effect on memory is different after consolidation and reconsolidation.

Of course, this pattern of results could possibly be explained, not as an effect of ZIP on reconsolidation, but rather as an effect of ZIP on extinction. Perhaps, somehow, ZIP enhanced the strength with which the subsequent second retrieval trial extinguishes the memory (evident in the third retrieval trial). To test this possibility and to control for any possible effects having to do with the relatively mild learning observed in both experimental and control groups displayed in Figure $3 b$, we performed an additional experiment in which we again infused ZIP into GC $45 \mathrm{~h}$ after retrieval, but delayed the next test for $24 \mathrm{~h}$. We found significant reduction in CTA memory in the ZIP-injected group compared with the control (Fig. $3 c ; t_{(7)}=5.2, p<0.01$ ), indicating that ZIP induced amnesia that cannot be seen after $3 \mathrm{~h}$ but is evident $24 \mathrm{~h}$ after the injection. Therefore, this effect is not due to effect on CTA extinction, but rather an effect on CTA memory maintenance reestablished after retrieval.

\section{Discussion}

We studied the interaction between memory retrieval and the maintenance mechanisms that are sensitive to ZIP, showing for the first time that memory retrieval interrupts maintenance, which then reemerges after reconsolidation in a manner similar but not identical to its emergence after consolidation.

We found that CTA becomes sensitive to ZIP injected into GC at $\sim 45 \mathrm{~h}$ after training, a time when memory has been suggested to have essentially reached completion (Rosenblum et al., 1993; Bambah-Mukku et al., 2014; Levitan et al., 2016). A memory retrieval trial immediately abolished the ZIP amnesic effect, presumably as a result of reconsolidation induction. As was true for consolidation induced by an acquisition trial, ZIP injections delivered $45 \mathrm{~h}$ after the onset of reconsolidation were again effective at causing amnesia. ZIPsensitive mechanisms induced after memory acquisition and retrieval appear to operate in the same time window for the induction of amnesia; they differ, however, in the latency with which the impact of ZIP is expressed.

\section{Temporal evolution of maintenance mechanisms sensitive to ZIP}

Several previous studies have demonstrated that ZIP has an amnesic effect on a fully consolidated memory despite having no impact on memory consolidation (Serrano et al., 2008; Migues et al., 2010; for review, see Kwapis and Helmstetter, 2014). Cortically based

CTA memory has been shown to be sensitive to ZIP by $3 \mathrm{~d}$ after memory acquisition and to remain so for at least 3 months, but to be immune to ZIP $3 \mathrm{~h}$ after acquisition (Shema et al., 2007, 2009). The current study allows us to better understand the temporal evolution of CTA maintenance mechanisms; the maintenance mechanisms that are sensitive to ZIP "come online" at approximately the time at which memory consolidation is completed (Rosenblum et al., 1993; Bambah-Mukku et al., 2014; Levitan et al., 2016). This finding confirms previous assertions that the processes of memory consolidation and maintenance are indeed differentiated temporally and mechanistically (Sacktor, 2011; Majumdar et al., 2012; Levitan et al., 2016).

The molecular mechanism(s) underlying this action of ZIP, which is not addressed in our dataset, is a matter of considerable controversy. ZIP was designed to mimic the pseudosubstrate sequence of the regulatory subunit of $\mathrm{PKC} \zeta$ and 


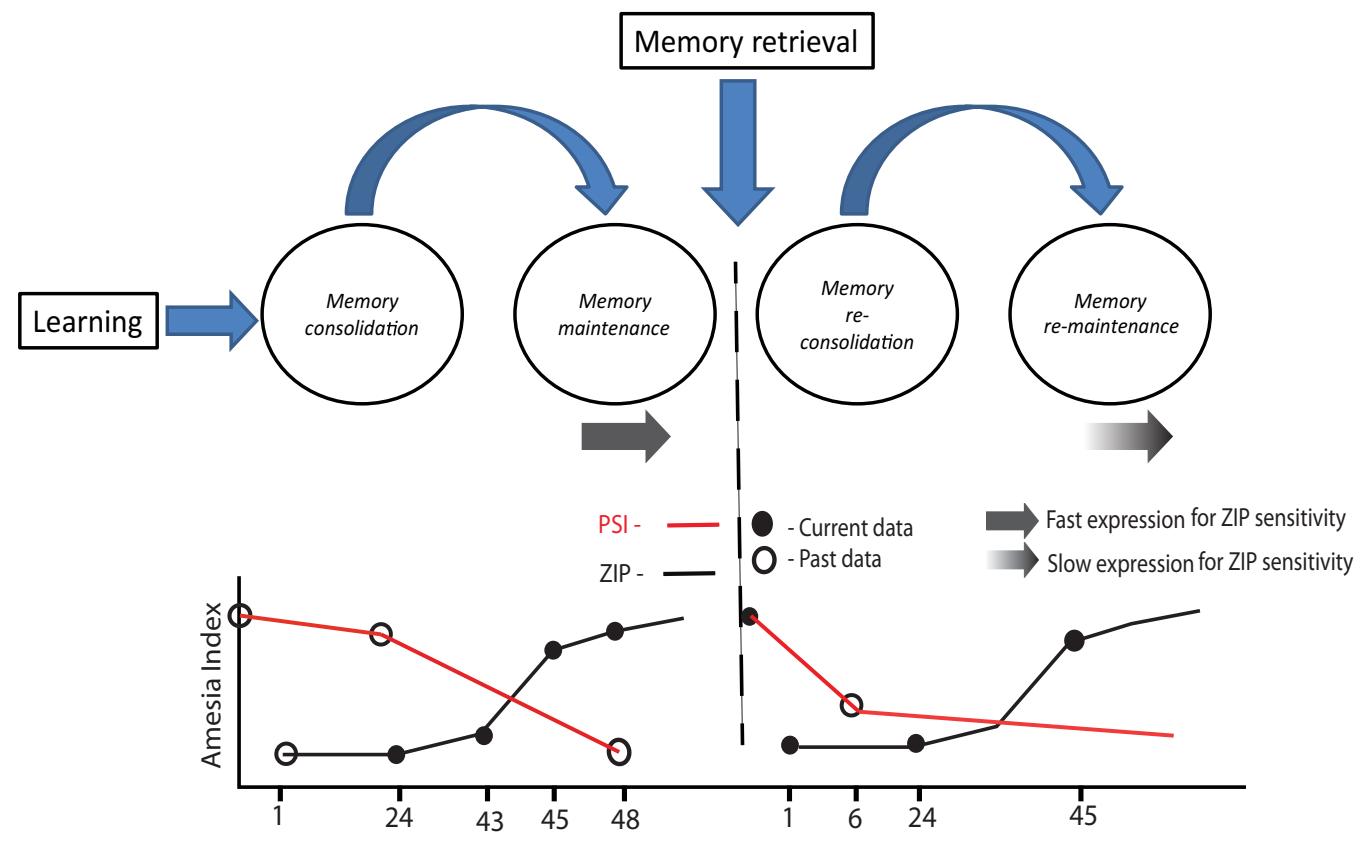

Figure 5. Model for the dynamic interaction between memory retrieval and ZIP-sensitive mechanisms. Here, we outline the consolidation and maintenance mechanisms that follow memory acquisition and reconsolidation and remaintenance mechanism that follow memory retrieval (top) by describing (bottom) their sensitivity to protein synthesis inhibitors (red lines) and ZIP (black lines). The sensitivity to protein synthesis inhibitors and ZIP is plotted as the amnesia index ( $y$-axis) as a function of time after memory acquisition and retrieval ( $x$-axis). Black closed time points represent data point from the current work and white open time points represents data points from past work (Rosenblum et al., 1993; Bambah-Mukku et al., 2014 for PSI sensitivity during consolidation. Nader and Hardt, 2009 for PSI sensitivity during reconsolidation. Shema et al., 2009 for ZIP sensitivity during consolidation). Full and gradient gray arrows represent latency to express ZIP sensitivity.

therefore may act through inhibition of PKM $\zeta$ (Sacktor, 2011). Recent data contest this possibility, however, showing that PKM $\zeta$ KO mice (Lee et al., 2013; Volk et al., 2013) express normal long-term memory and that memory maintenance in these mice is still sensitive to ZIP. Several other possible mechanisms have been proposed, including a feedback mechanism through other PKC $\zeta$ isoforms (Tsokas et al., 2016). Furthermore, the recent demonstration that ZIP administration affects network activity directly in vivo (LeBlancq et al., 2016) suggests that the quest for memory maintenance mechanisms could also "live" at the systems level. Regardless of the heated debate concerning ZIP's targets, there is no doubt that ZIP influences memory maintenance, a fact that makes it a valuable tool for the neuroscientist interested in learning and memory.

\section{Memory retrieval influences the maintenance mechanisms that are sensitive to ZIP}

Memory retrieval has long been known to have profound effects on the memory trace (Spear, 1973). Only recently, however, has the process of reconsolidation underlying this effect been elucidated (for review, see Nader and Hardt, 2009; Alberini and Ledoux, 2013). This process, which is initiated by the action of memory retrieval, modifies memory content (Rao-Ruiz et al., 2011), strength (Inda et al., 2011; Fukushima et al., 2014) and persistence (Levitan et al., 2010); memory transiently returns to a labile state wherein novel protein synthesis is required if the memory is to be retained (hence "reconsolidation").

Reconsolidation has been suggested to be similar, but not identical, to memory consolidation (Alberini, 2005; Alberini and Ledoux, 2013) and our work provides novel support for both parts of this hypothesis, thereby elucidating the relationship be- tween processes sensitive to ZIP (Sacktor, 2011; Kwapis and Helmstetter, 2014) and those set in motion by memory retrieval (Nader and Hardt, 2009; Alberini and Ledoux, 2013), a relationship that has never before been studied in detail (Nader and Hardt, 2009; Kwapis and Helmstetter, 2014). First, we showed, consistent with previous work (Eisenberg et al., 2003), that CTA memory retrieval can induce a reconsolidation process that depends on protein synthesis in GC. We went on to show that memory retrieval and the attendant initiation of reconsolidation (Fig. 3 and Nader and Hardt, 2009) abolishes the ability of ZIP to induce amnesia, demonstrating that memory retrieval disrupts maintenance mechanisms sensitive to ZIP; ZIP sensitivity reemerged $45 \mathrm{~h}$ after retrieval, a temporal evolution that is reminiscent of that observed after memory acquisition. Therefore, our data suggest a model in which the impact of the mechanisms taking place after memory acquisition and retrieval are similar.

How might memory retrieval disrupt the maintenance mechanisms that are sensitive to ZIP? At present, we can only speculate. The ZIP amnesic effect has been correlated with its ability to inhibit GluR2 receptor trafficking to potentiated synapses (Yao et al., 2008; Migues et al., 2010). GluR2 trafficking out of and into the synapse is induced by memory retrieval and is important for reconsolidation process (Rao-Ruiz et al., 2011; Hong et al., 2013). Therefore, it is reasonable to propose that memory retrieval somehow disrupts the ability of ZIP to modulate the availability of GluR2 proteins or its trafficking machinery at the synapse. However, this explanation cannot be the whole story: the fact that the influence of memory retrieval on GluR2 trafficking ends after $<24$ h (Rao-Ruiz et al., 2011; Hong et al., 2013), a time frame when the ZIP amnesic effect is still absent, suggests that there must be additional cellular processes that inhibit ZIP-sensitive mechanisms. 
The current data should aid in the future elucidation of these mechanisms. Alas, it is clear that this is far from a simple task, a fact driven home by the conflicting proposals found in the recent literature (Lee et al., 2013; Volk et al., 2013; Sadeh et al., 2015; LeBlancq et al., 2016; Tsokas et al., 2016). Of course, memory maintenance spans days to a lifetime, whereas memory consolidation (which has been well described molecularly) is confined to just few hours (Alberini, 2009; Nader and Hardt, 2009; Gal-BenAri et al., 2012). This fact and the fact that network dynamics demonstrate substantial flux in over the life time of a memory (Ziv et al., 2013; Moran and Katz, 2014) implies that the identity of neurons and networks involved in maintaining a memoryand thus the identity of the cellular processes_-may change with the passage of time. A further complication arises from a recent study demonstrating that ZIP may influence network activity directly in vivo (LeBlancq et al., 2016). Future experiments should examine both molecular and network dynamics in the same preparation, for example, by genetically targeting defined populations of neurons while recording and analyzing those same neurons.

Our data further suggest that maintenance after consolidation and maintenance after reconsolidation are not identical. A disruption of maintenance can be observed within $3 \mathrm{~h}$ of ZIP infusion after memory acquisition, but, after memory retrieval, the delay between ZIP infusion and maintenance disruption is longer. This suggests that the cascade of events set in motion by ZIP infusion may differ depending on context. Indeed, memory acquisition and retrieval, despite initiating similar general processes such as protein synthesis, almost certainly differ at the level of specifics - that is, in the identity of the relevant proteins (Alberini, 2005), in the brain regions that are engaged (Bahar et al., 2004) and in the local circuits that are activated (Ziv et al., 2013; Moran and Katz, 2014).

In conclusion, the data described here allow us to present a model (Fig. 5) of the ZIP-sensitive mechanisms induced after memory acquisition and retrieval. Memory acquisition and retrieval induce consolidation and reconsolidation (respectively), both protein-synthesis-dependent and ZIP-insensitive processes, but both followed by maintenance processes (induced both after memory acquisition and retrieval) that are sensitive to ZIP and not dependent on protein synthesis. However, the latency to express ZIP-induced amnesia is smaller after memory acquisition than after memory retrieval, indicating that the maintenance mechanisms that are sensitive to ZIP are different after memory acquisition and retrieval.

\section{References}

Alberini CM (2005) Mechanisms of memory stabilization: are consolidation and reconsolidation similar or distinct processes? Trends Neurosci 28:51-56. CrossRef Medline

Alberini CM, Ledoux JE (2013) Memory reconsolidation. Curr Biol 23: R746-R750. CrossRef Medline

Alberini CM (2009) Transcription factors in long-term memory and synaptic plasticity. Physiol Rev 89:121-145. CrossRef Medline

Bahar A, Dorfman N, Dudai Y (2004) Amygdalar circuits required for either consolidation or extinction of taste aversion memory are not required for reconsolidation. Eur J Neurosci. 19:1115-1118. CrossRef Medline

Bambah-Mukku D, Travaglia A, Chen DY, Pollonini G, Alberini CM (2014) A positive autoregulatory BDNF feedback loop via C/EBPbeta mediates hippocampal memory consolidation. J Neurosci 34:12547-12559. CrossRef Medline

Berman DE, Dudai Y (2001) Memory extinction, learning anew, and learning the new: dissociations in the molecular machinery of learning in cortex. Science 291:2417-2419. CrossRef Medline

Dudai Y (2006) Reconsolidation: the advantage of being refocused. Curr Opin Neurobiol 16:174-178. CrossRef Medline
Eisenberg M, Kobilo T, Berman DE, Dudai Y (2003) Stability of retrieved memory: inverse correlation with trace dominance. Science 301:11021104. CrossRef Medline

Fukushima H, Zhang Y, Archbold G, Ishikawa R, Nader K, Kida S (2014) Enhancement of fear memory by retrieval through reconsolidation. Elife 3:e02736. CrossRef Medline

Gal-Ben-Ari S, Rosenblum K (2011) Molecular mechanisms underlying memory consolidation of taste information in the cortex. Front Behav Neurosci 5:87. CrossRef Medline

Gal-Ben-Ari S, Kenney JW, Ounalla-Saad H, Taha E, David O, Levitan D, Gildish I, Panja D, Pai B, Wibrand K, Simpson TI, Proud CG, Bramham CR, Armstrong JD, Rosenblum K (2012) Consolidation and translation regulation. Learn Mem 19:410-422. CrossRef Medline

Hong I, Kim J, Kim J, Lee S, Ko HG, Nader K, Kaang BK, Tsien RW, Choi S. AMPA receptor exchange underlies transient memory destabilization on retrieval (2013) Proc Natl Acad Sci U S A 110:8218-8223. CrossRef

Inda MC, Muravieva EV, Alberini CM (2011) Memory retrieval and the passage of time: from reconsolidation and strengthening to extinction. J Neurosci 31:1635-1643. CrossRef Medline

Katz DB, Simon SA, Nicolelis MA (2001) Dynamic and multimodal responses of gustatory cortical neurons in awake rats. J Neurosci 21:44784489. Medline

Kwapis JL, Helmstetter FJ (2014) Does PKM (zeta) maintain memory? Brain Res Bull 105:36-45. CrossRef Medline

LeBlancq MJ, McKinney TL, Dickson CT (2016) ZIP it: neural silencing is an additional effect of the PKM-zeta inhibitor zeta-inhibitory peptide. J Neurosci 36:6193-6198. CrossRef Medline

Lee AM, Kanter BR, Wang D, Lim JP, Zou ME, Qiu C, McMahon T, Dadgar J, Fischbach-Weiss SC, Messing RO (2013) Prkcz null mice show normal learning and memory. Nature 493:416-419. CrossRef Medline

Levitan D, Twitto R, Levy R, Lyons LC, Susswein AJ (2010) A brief retraining regulates the persistence and lability of a long-term memory. Learn Mem 17:402-406. CrossRef Medline

Levitan D, Gal-Ben-Ari S, Heise C, Rosenberg T, Elkobi A, Inberg S, Sala C, Rosenblum K (2016) The differential role of cortical protein synthesis in taste memory formation and persistence. NPJ Science of Learning $1: 16001$

Majumdar A, Cesario WC, White-Grindley E, Jiang H, Ren F, Khan MR, Li L, Choi EM, Kannan K, Guo F, Unruh J, Slaughter B, Si K (2012) Critical role of amyloid-like oligomers of Drosophila Orb2 in the persistence of memory. Cell 148:515-529. CrossRef Medline

Migues PV, Hardt O, Wu DC, Gamache K, Sacktor TC, Wang YT, Nader K (2010) PKMzeta maintains memories by regulating GluR2dependent AMPA receptor trafficking. Nat Neurosci 13:630-634. CrossRef Medline

Moran A, Katz DB (2014) Sensory cortical population dynamics uniquely track behavior across learning and extinction. J Neurosci 34:1248-1257. CrossRef Medline

Nader K, Schafe GE, Le Doux JE (2000) Fear memories require protein synthesis in the amygdala for reconsolidation after retrieval. Nature 406: 722-726. CrossRef Medline

Nader K, Hardt OA (2009) single standard for memory: the case for reconsolidation. Nat Rev Neurosci 10:224-234. CrossRef Medline

Paxinos G, Watson C (2007) The rat brain in stereotaxic coordinates, Ed 6. San Diego: Academic.

Rao-Ruiz P, Rotaru DC, van der Loo RJ, Mansvelder HD, Stiedl O, Smit AB, Spijker S (2011) Retrieval-specific endocytosis of GluA2-AMPARs underlies adaptive reconsolidation of contextual fear. Nat Neurosci 14: 1302-1308. CrossRef Medline

Rosenblum K, Meiri N, Dudai Y (1993) Taste memory: the role of protein synthesis in gustatory cortex. Behav Neural Biol 59:49-56. CrossRef Medline

Sacktor TC (2011) How does PKMzeta maintain long-term memory? Nat Rev Neurosci 12:9-15. CrossRef Medline

Sadeh N, Verbitsky S, Dudai Y, Segal M (2015) Zeta inhibitory peptide, a candidate inhibitor of protein kinase $\mathrm{M} \zeta$, Is excitotoxic to cultured hippocampal neurons. J Neurosci 35:12404-12411. CrossRef Medline

Sara SJ (2000) Retrieval and reconsolidation: toward a neurobiology of remembering. Learn Mem 7:73-84. CrossRef Medline

Serrano P, Friedman EL, Kenney J, Taubenfeld SM, Zimmerman JM, Hanna 
J, Alberini C, Kelley AE, Maren S, Rudy JW, Yin JC, Sacktor TC, Fenton AA (2008) PKMzeta maintains spatial, instrumental, and classically conditioned long-term memories. PLoS Biol 6:2698-2706. CrossRef Medline

Shema R, Sacktor TC, Dudai Y (2007) Rapid erasure of long-term memory associations in the cortex by an inhibitor of PKM zeta. Science 317:951953. CrossRef Medline

Shema R, Hazvi S, Sacktor TC, Dudai Y (2009) Boundary conditions for the maintenance of memory by PKMzeta in neocortex. Learn Mem 16:122_ 128. CrossRef Medline

Spear NE (1973) Retrieval of memory in animals. Psychol Rev 80:163-194.

Tsokas P, Hsieh C, Yao Y, Lesburguères E, Wallace EJ, Tcherepanov A, Jothianandan D, Hartley BR, Pan L, Rivard B, Farese RV, Sajan MP, Bergold PJ,
Hernández AI, Cottrell JE, Shouval HZ, Fenton AA, Sacktor TC (2016) Compensation for $\mathrm{PKM} \zeta$ in long-term potentiation and spatial long-term memory in mutant mice. Elife 5: pii: e14846. CrossRef Medline

Volk LJ, Bachman JL, Johnson R, Yu Y, Huganir RL (2013) PKM- $\zeta$ is not required for hippocampal synaptic plasticity, learning and memory. Nature 493:420-423. CrossRef Medline

Yao Y, Kelly MT, Sajikumar S, Serrano P, Tian D, Bergold PJ, Frey JU, Sacktor TC (2008) PKM zeta maintains late long-term potentiation by $N$ ethylmaleimide-sensitive factor/GluR2-dependent trafficking of postsynaptic AMPA receptors. J Neurosci 28:7820-7827. CrossRef Medline

Ziv Y, Burns LD, Cocker ED, Hamel EO, Ghosh KK, Kitch LJ, El Gamal A, Schnitzer MJ (2013) Long-term dynamics of CA1 hippocampal place codes. Nat Neurosci 16:264-266. CrossRef Medline 